\title{
SPATIO-TEMPORAL ANALYSIS OF URBAN HEAT ISLAND IN MANDAUE CITY, PHILIPPINES
}

\author{
A. M. Rejuso ${ }^{1, *}$, A. C. Cortes ${ }^{2}$, A. C. Blanco ${ }^{1,3}$, C. A. Cruz ${ }^{1}$, J. B. Babaan ${ }^{1}$ \\ ${ }^{1}$ UP Training Center for Applied Geodesy and Photogrammetry, College of Engineering, University of the Philippines, Diliman, \\ Quezon City 1101- *rejarnold.ajr@gmail.com, (acblanco, cacruz7, jbbabaan) @up.edu.ph \\ ${ }^{2}$ Department of Biology and Environmental Science, College of Science \\ University of the Philippines Cebu, Cebu City, Philippines - accortes@up.edu.ph \\ ${ }^{3}$ Department of Geodetic Engineering, University of the Philippines, Diliman, Quezon City
}

\section{Commission IV}

KEY WORDS: Climate Engine, land surface temperature, urban thermal environment, normalized built-up index, normalized vegetation index, normalized water index

\begin{abstract}
:
Extensive urbanization alters the natural landscape as vegetation were replaced with infrastructures composed of materials with low albedo and high heat capacity often resulting to increase in land surface temperatures (LST). The present study focused on the spatial and temporal variations of LST in Mandaue City, one of the metropolitan cities in the Philippines that had undergone a rapid rate of urbanization over the past years. Climate Engine (CE), a cloud computing tool that processes satellite images, was used in this study. Preprocessed LST, normalized difference water index (NDWI), normalized difference vegetation index (NDVI), shortwave infrared (SWIR 1) and near-infrared (NIR) layers were directly downloaded from CE while the normalized difference built-up index (NDBI) maps were calculated. Time-series dataset of these indices were analyzed to determine the impacts of reduced vegetation cover and increased built-up areas on surface temperature from years 2013 to 2019. The spatial distribution of LST were analyzed using Univariate Local Moran's I in GeoDa to identify hotspots within the city. Analysis results showed that the hotspots are barangays Tipolo (100\%), Bakilid (100\%), Ibabao-Estancia (93.5\%), Alang-Alang (87.2\%), Guizo (84.4\%), Subangdaku (84.1\%), and Centro (79.4\%). The results indicated that there is a linear relationship between LST and NDBI $(r=0.659, p<0.01)$ while an inverse relationship was observed between LST with NDVI $(r=-0.527, p<0.1)$ and NDWI $(r=-0.620, p<0.01)$.
\end{abstract}

\section{INTRODUCTION}

The global trend in extensive urbanization has drastically increased. Natural habitats and vegetation are altered into settlements to meet the demand of the increasing human population. These changes in surface composition and characteristics have a massive impact on the thermodynamics of the environment and atmosphere affecting the energy and water balance. (Oke, 1988; Santamouris, 2013). The continuous increase of conventional urban infrastructures and diminished portion of vegetative surfaces have resulted into the increase of land surface temperatures (LST) in urban areas (Gartland, 2012; Jamei, Rajagopalan, \& Sun, 2019). This led to a unique phenomenon called urban heat island (UHI) wherein the urban environment exhibits a different microclimate that has higher ambient air and land surface temperatures compared to the rural surroundings (Mihalakakou, Flocas, Santamouris, \& Helmis, 2002; Oke, 1982; Yang, Qian, Song, \& Zheng, 2016) .

UHI is determined by the local weather conditions and nature of the urban area such as material composition, topography, and geographical location (Gartland, 2012). The intensity of the urban heat island (UHII) varies from city to city (Levermore, Parkinson, Lee, Laycock, \& Lindley, 2018).

UHI is now regarded as one of the major environmental issues. It gained much concern and enticed governments in increasing the research efforts to study, mitigate and possibly prevent intense UHI effects in their respective metropolitan areas. The most common approach to UHI research is through the use of remote sensing technology such as satellite and aerial drones (Gartland, 2012; Macarof \& Statescu, 2017).
Remote sensing technology has great capability in investigating the spatial and temporal variability of UHI (Fathizad, Tazeh, Kalantari, \& Shojaei, 2017; Gartland, 2012; Macarof \& Statescu, 2017; Voogt \& Oke, 2003). Modern satellite imagery such as Moderate Resolution Imaging Spectroradiometer (MODIS) and Landsat provide numerous data that are used in the calculation of LST, and generation of various indices such as normalized difference built-up index (NDBI), normalized difference water index (NDWI), and normalized difference vegetation index (NDVI) (Deilami, Kamruzzaman, \& Liu, 2018; Kaplan, Avdan, \& Yigit Avdan, 2018; Orhan, Ekercin, \& Dadaser-Celik, 2014; Zhou \& Chen, 2018). These indices are essential in explaining the spatial and temporal characteristics of UHI. Numerous studies have already discovered and established the relationship between these indices to LST (Hasanlou \& Mostofi, 2015; Jamei et al., 2019; Kikon, Singh, Singh, \& Vyas, 2016).

Satellite imagery specifically from Landsat is utilized in this study for the analysis of UHI. Furthermore, Climate Engine (CE) which is a cloud computing and visualization tool that already pre-processes satellite images, is used in this study. CE has a streamlined usage capability over other computing engines and as such researchers now are starting to adopt this new methodology. CE datasets are derived from existing image collections such as Landsat, MODIS and Sentinel in Google Earth Engine that have already undergone calibration and precomputation (Huntington et al., 2017).

UHI research in the Philippines is quite limited particularly in Mandaue City wherein there is no published study yet. This paper intends to determine the occurrence of UHI in Mandaue City. The objectives of the study are: 1 .) to analyze the spatial and temporal variations of LST in Mandaue City; 2.) to examine the relationships between LST with NDBI, NDWI, and NDVI 
through the use of scatterplots and Pearson's correlation test; and, 3.) to identify hotspots within Mandaue city through the use of Univariate Local Moran's I statistics.

\section{METHODS}

\subsection{Description of the study area}

Mandaue City, Cebu, Philippines is situated in the eastern coastal plains of Cebu province located at 109' 40.34" N, 123 5' 28.16" $\mathrm{E}$ (Figure 1) with an average elevation of $16.8 \mathrm{~m}$ above sea level. It has a land area of $34.87 \mathrm{~km}^{2}$. It is comprised of twenty-seven barangays and a city administered area namely PUD I. It is recognised as the most industrialized city in Metro Cebu. It is known as the focal point of manufacturing in the Philippines and considered as the industrial hub in Cebu province hosting around 20,000 industrial and commercial establishments (Castillo, 2018). It is predominantly comprised of built-up areas with less vegetation cover as shown in Figure 1. Mangrove forests constitute most of its remaining vegetation cover that are located at the southeast area of Mandaue City along the Mactan Channel.

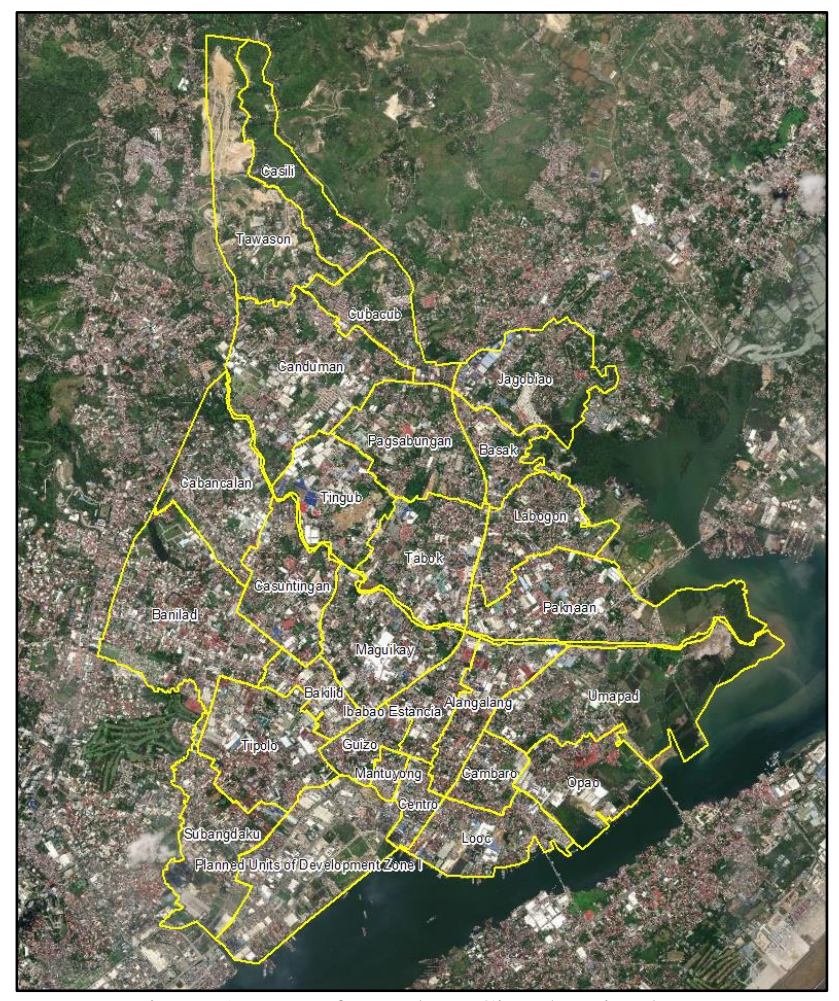

Figure 1. Map of Mandaue City showing barangay boundaries

\subsection{Data processing and analysis workflow}

The methodology of this research, as shown in Figure 2, is organized into the following:

(1) retrieval of LST, NDVI, NDWI, SWIR and NIR band layers from CE,

(2) generation of NDBI layer from SWIR and NIR band layers,

(3) calculation of the mean values of LST and indices per barangay and per $100 \mathrm{~m} \times 100 \mathrm{~m}$ grid,

(4) examination of the relationships between LST and the indices,

(5) and lastly, determination of hotspots in Mandaue City.

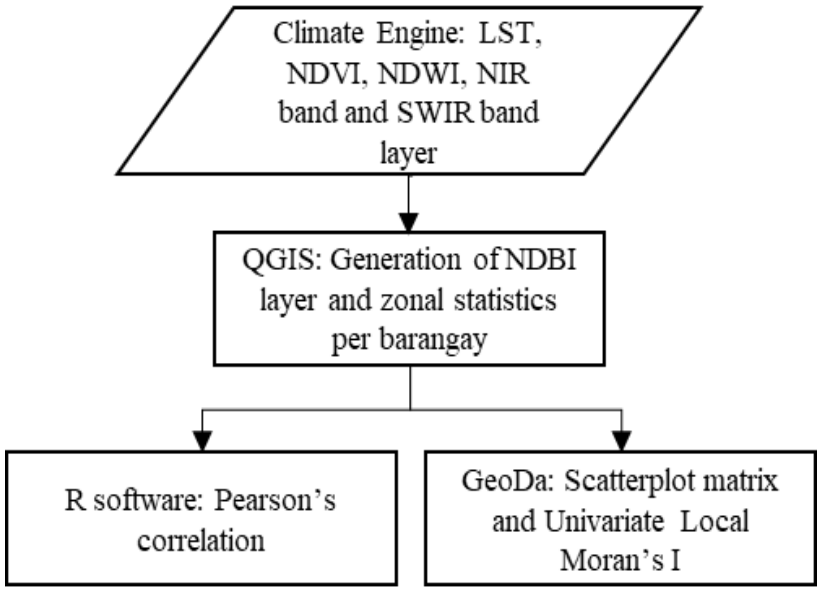

Figure 2. Workflow for investigating relationship among LST and land cover distribution

\subsection{Data retrieval and generation}

Pre-processed LST, NDWI, NDVI, SWIR 1 and NIR map layers from year 2013 to 2019 were directly downloaded from CE. Details of the satellite images used in this study are provided in Table 1.

\begin{tabular}{|c|c|c|c|}
\hline Data used & $\begin{array}{l}\text { Data } \\
\text { acquisition } \\
\text { year }\end{array}$ & $\begin{array}{l}\text { Satellite } \\
\text { Path/Row }\end{array}$ & Data source \\
\hline $\begin{array}{l}\text { Landsat } 7 \text { and } 8 \\
\text { (Top Of } \\
\text { Atmosphere): } \\
\text { LST, NDWI, } \\
\text { NDVI, SWIR } 1 \\
\text { and NIR layers }\end{array}$ & $\begin{array}{l}2013,2014, \\
2015,2016, \\
2017 \& \\
2018\end{array}$ & $113 / 53$ & $\begin{array}{l}\text { Climate Engine } \\
\text { (https://app.clim } \\
\text { ateengine.org/) }\end{array}$ \\
\hline
\end{tabular}

Table 1. Data specification, acquisition and source of satellite images used

\subsubsection{NDVI}

NDVI is the most commonly used index to estimate vegetation cover based on the NIR and Red bands as shown in Equation 1. NDVI values range from -1 to +1 . NDVI values close to zero correspond to a built-up area while values close to +1 indicate the highest possible density of green vegetation (Isa, Wan Mohd, \& Salleh, 2013; Liu \& Zhang, 2011).

$$
\mathrm{NDVI}=\frac{\mathrm{NIR}-\mathrm{RED}}{\mathrm{NIR}+\mathrm{RED}}
$$

Where,

$$
\begin{aligned}
& \mathrm{NIR}=\text { near-infrared reflectance } \\
& \mathrm{RED}=\text { red reflectance }
\end{aligned}
$$

\subsubsection{NDWI}

NDWI can be classified under two types: (1) emphasis on open water bodies excluding the presence of moisture in soil and vegetation, and (2) focus on moisture content in plants and soil. The latter is used in this study because it is a good indicator of vegetation health and also there are no large freshwater bodies in Mandaue City. This type of NDWI uses NIR and SWIR bands as shown in Equation 2. NDWI values range from -1 to +1 . High NDWI values indicate high vegetation water content. On the 
other hand, negative NDWI values correspond to low vegetation water content and possible vegetation water stress (Gao, 1996).

$$
\mathrm{NDWI}=\frac{\mathrm{NIR}-\mathrm{SWIR} 1}{\mathrm{NIR}+\mathrm{SWIR} 1}
$$

Where, $\quad$ SWIR1 = shortwave infrared 1 reflectance

\subsubsection{Generation of the NDBI layer}

NDBI is the commonly used indicator to extract the built-up areas in cities. Calculation of NDBI layers are based from the SWIR 1 and NIR band layers as displayed in Equation 3 (Za, Gao, \& $\mathrm{Ni}$, 2003). NDBI values ranges from -1 to +1 . High values of NDBI correspond to highly built-up areas ( $\mathrm{Za}, \mathrm{Gao}, \& \mathrm{Ni}, 2003)$.

$$
\mathrm{NDBI}=\frac{\text { SWIR1 }-\mathrm{NIR}}{\mathrm{SWIR} 1+\mathrm{NIR}}
$$

\subsection{Data analysis}

Scatterplot matrix was used to determine and visualize the bivariate relationships between LST, NDBI, NDVI, and NDWI. Pearson's correlation was performed to further examine the relationships among LST, NDBI, NDVI and NDWI. A positive Pearson's coefficient, $r$, indicates a direct relationship while a negative $r$ indicates an inverse relationship. The strength of the relationship also varies depending on the $r$ value. A strong relationship is indicated when the $r$ value is above 0.7 or near 1 , a moderate relationship is indicated when the $r$ value is below 0.7 and above 0.5 , while a weak relationship is indicated when the $r$ value is below 0.5 .

The study area was divided into $100 \mathrm{~m} \times 100 \mathrm{~m}$ using the QGIS processing toolbox to conduct a grid level analysis in calculating the average LST, NDBI, NDVI and NDWI. This analysis was performed to thoroughly investigate the changes per pixel with an area of $100 \mathrm{~m} \times 100 \mathrm{~m}$ compared to the large polygon area per barangay (Kikon et al., 2016). Furthermore, Univariate Local Moran's I was used for spatial autocorrelation in identifying hot spots and cold spots in Mandaue City. The determination and calculation of the \% hotspot or coldspot in a barangay is displayed in Equation 4.

$$
\% \text { hotspot or coldspot }=\mathrm{SP} / \mathrm{TBP}
$$

Where,

$$
\mathrm{SP}=\text { number of significant pixels }
$$$$
\mathrm{TBP}=\text { total barangay pixel count }
$$

\section{RESULTS AND DISCUSSION}

\subsection{LST}

Annual average LST at the barangay level is shown in Figure 3, where values on the bottom-right corner indicate annual average for the entire city. The highest average LST $\left(40.6^{\circ} \mathrm{C}\right)$ was observed in 2016 while lowest average LST $\left(33.5^{\circ} \mathrm{C}\right)$ was observed in 2013 (Figure 4). Further, lower average LSTs were observed during 2013,2017, and 2018, which could be due to the high number of tropical cyclones that entered the Philippine Area of Responsibility (PAR) during those years. According to the Philippine Atmospheric, Geophysical and Astronomical Services Administration (PAGASA, 2019), there were 25 tropical cyclones during 2013, 22 tropical cyclones during 2017 and 21 tropical cyclones during 2018 compared to the 19 tropical cyclones during 2014, 15 tropical cyclones during 2015, and 14 tropical cyclones during 2016. It is possible that during those years, most Landsat 7 and Landsat 8 imageries of Mandaue City are exhibiting higher percentage cloud cover resulting to anomalous or lower annual LSTs.

The average LST values in Mandaue City ranges from $30.0{ }^{\circ} \mathrm{C}-$ $44.0{ }^{\circ} \mathrm{C}$ (Figure 3). The barangays have higher average LST namely Tipolo $\left(39.0{ }^{\circ} \mathrm{C}\right)$, Bakilid $\left(38.8{ }^{\circ} \mathrm{C}\right)$, Ibabao-Estancia $\left(38.7^{\circ} \mathrm{C}\right)$, Alang-Alang $\left(38.7^{\circ} \mathrm{C}\right)$, Guizo $\left(38.4^{\circ} \mathrm{C}\right)$, Centro $(38.4$ $\left.{ }^{\circ} \mathrm{C}\right)$, Casuntingan $\left(38.2^{\circ} \mathrm{C}\right)$, Banilad $\left(38.2^{\circ} \mathrm{C}\right)$, Cambaro (38.1 $\left.{ }^{\circ} \mathrm{C}\right)$, Maguikay $\left(38.1^{\circ} \mathrm{C}\right)$ and Subangdaku $\left(38.0^{\circ} \mathrm{C}\right)$ are highly built-up areas classified under the residential, commercial and industrial sector. On the other hand, vegetated barangays like Casili $\left(32.8^{\circ} \mathrm{C}\right)$, Paknaan $\left(34.7^{\circ} \mathrm{C}\right)$ and Umapad $\left(34.9^{\circ} \mathrm{C}\right)$ have lower average LSTs. The vegetation cover in barangay Casili is comprised of terrestrial plants while in barangays Paknaan and Umapad are comprised of both terrestrial plants and mangroves based on the satellite images accessed via Google Earth.

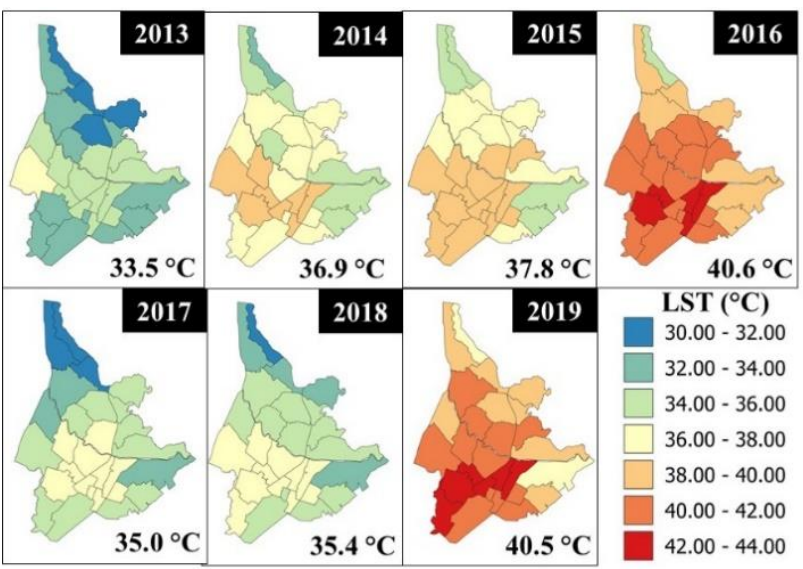

Figure 3. Barangay-level average LST maps of Mandaue City

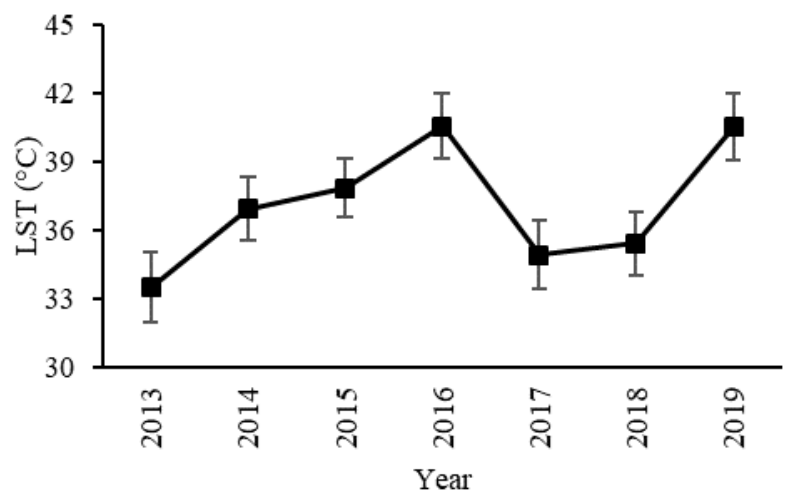

Figure 4. Annual average LST in Mandaue City, 2013-2019

\subsection{NDBI}

Barangay level annual average NDBI is shown in Figure 5. The annual average NDBI for the entire city are placed at the bottomright corner. The average NDBI values in Mandaue City range from -0.3 to 0.0 indicating that there is a mixed composition of impervious surfaces and bare soil. The negative NDBI values could be attributed to the zonal statistics mean computation. The NDBI spatial pattern shows a clear distinction between areas with dense urban structures and therefore higher NDBI values like barangay Alang-Alang (-0.1), Bakilid (0.0), Cambaro (-0.1), 
Centro (0.0), Guizo (0.0), Ibabao-Estancia (-0.1), Labogon (-0.1), Looc (0.0), Mantuyong (0.0), PUD I (-0.1), Subangdaku (0.0), Tingub (-0.1) and Tipolo (0.0)and a highly vegetated barangay with less urban structures like barangay Casili (-0.2).

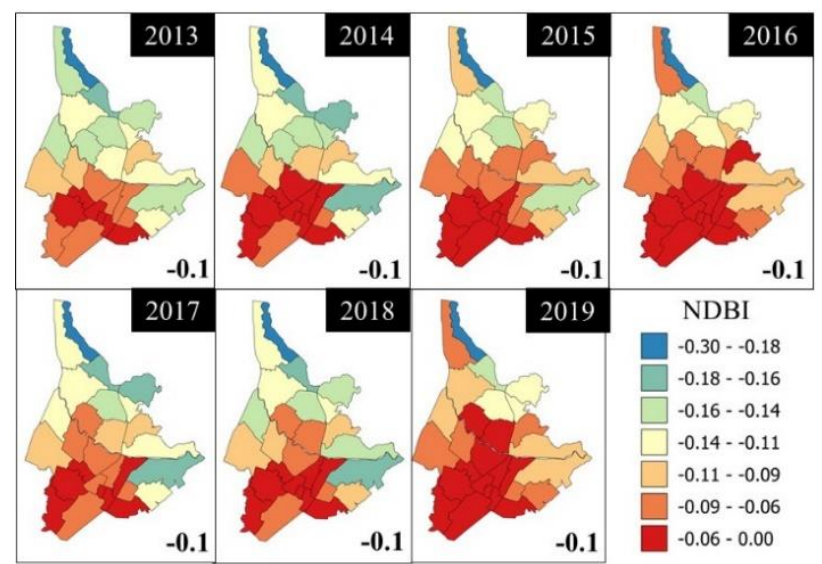

Figure 5. Barangay-level average NDBI maps of Mandaue City

\subsection{NDVI}

Barangay level annual average NDVI is displayed in Figure 6. The values on the bottom-right corner indicate annual average NDVI for the entire city. The average NDVI values in Mandaue City range from 0.2 to 0.8 indicating that there are low and high vegetation cover barangays in Mandaue City. Most barangays located at the southwest part of Mandaue City namely barangay Bakilid (0.2), Mantuyong (0.2), Centro (0.2), Looc (0.2), Tipolo (0.3), Ibabao-Estancia (0.3), PUD I (0.3), Alang-Alang (0.3), Guizo (0.3), Opao (0.3), Subangdaku (0.3), Maguikay (0.3), Cambaro (0.3), Cansuntingan (0.3), and Banilad (0.3) have low average NDVI values because these are built-up areas. The barangays with high average NDVI values are barangay Casili (0.7), Cubacub (0.5), and Tawason (0.5) indicating that these areas are highly vegetated with shrubs, grass and trees.

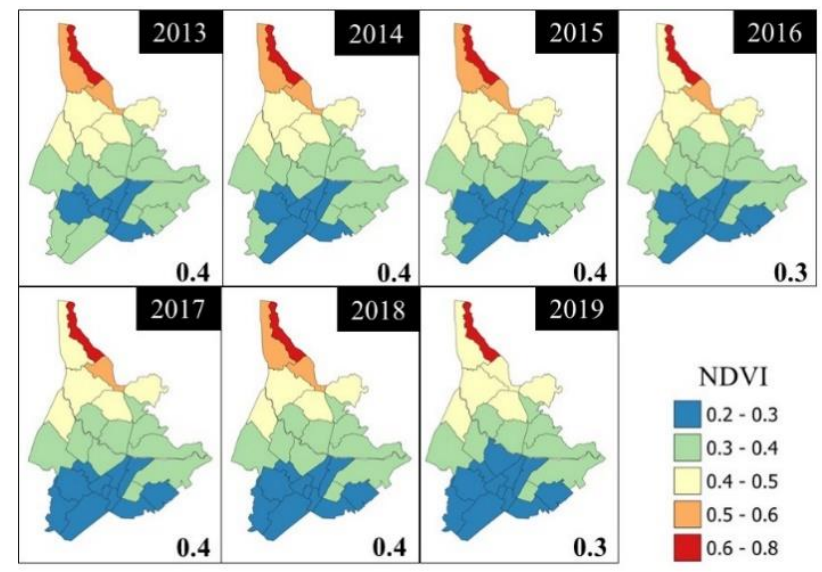

Figure 6. Barangay-level average NDVI maps of Mandaue City

\subsection{NDWI}

Annual average NDWI at the barangay level is displayed in Figure 7. Values on the bottom-right corner indicate annual average NDWI for the entire city. The average NDWI values in Mandaue range from 0.06 to 0.42 . NDWI is associated to the amount of moisture present in vegetative areas thus areas with less vegetation have low NDWI values. Barangays Alang-Alang (0.1), Bakilid (0.1), Cambaro (0.1), Centro (0.1), Guizo (0.1), Ibabao-Estancia (0.1), Looc (0.1), Maguikay (0.1), Mantuyong (0.1), PUD I (0.1), Subangdaku (0.1) and Tipolo (0.1) have low NDWI values because these are mostly composed of impervious surfaces that cannot hold moisture while vegetated barangays Casili (0.4), Umapad (0.3), and Cubacub (0.3) have high average NDWI values.

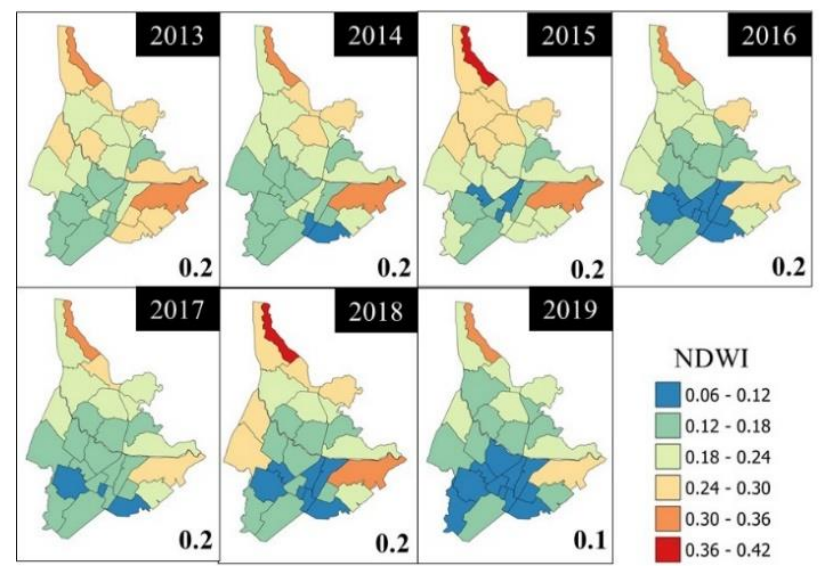

Figure 7. Barangay-level average NDWI maps of Mandaue City

\subsection{RELATIONSHIP BETWEEN LST, NDBI, NDVI, and NDWI}

The scatterplots are presented in Figure 8. The slopes of linear fit are also presented in Figure 8 in which the significance level is indicated by two $*^{*}(p<0.01)$. The results suggested that there is a direct relationship between LST and NDBI with a slope of $0.816(p<0.01)$ indicating that built-up areas have high surfaces temperatures. On the other hand, negative relationships were observed between LST and NDVI with a slope of -0.774 ( $p<$ 0.01 ) suggesting that areas with vegetations have low surface temperatures. Furthermore, a negative relationship was observed between LST and NDWI with a slope of $-0.902(p<0.01)$ indicating that areas with high amount of moisture in the soil or vegetation have low surface temperatures. There is a positive correlation between LST and NDBI $(r=0.659, p<0.01)$ that further supports the results of the scatterplot and slope of linear fit that as built-up areas increase, surface temperatures will also increase within those areas (Table 2). On the other hand, negative correlations are observed between LST with NDVI $(r=-0.527$, $\mathrm{p}<0.1)$ and NDWI $(r=-0.620, p<0.01)$ indicating that areas with vegetation and high moisture levels have low surface temperatures. Based on higher Pearson's coefficient and slope of linear fit values of NDWI compared to NDVI, NDWI can be considered as a better indicator than NDVI in relation with LST in the case of Mandaue City due to less vegetation cover in Mandaue City. The moisture in the soil and vegetation play a big role in mitigating the effects of LST. Evaporation of moisture in the soil and evapotranspiration of moisture in plants produce a cooling effect that dissipates the heat energy into water vapour (Gartland, 2012). 


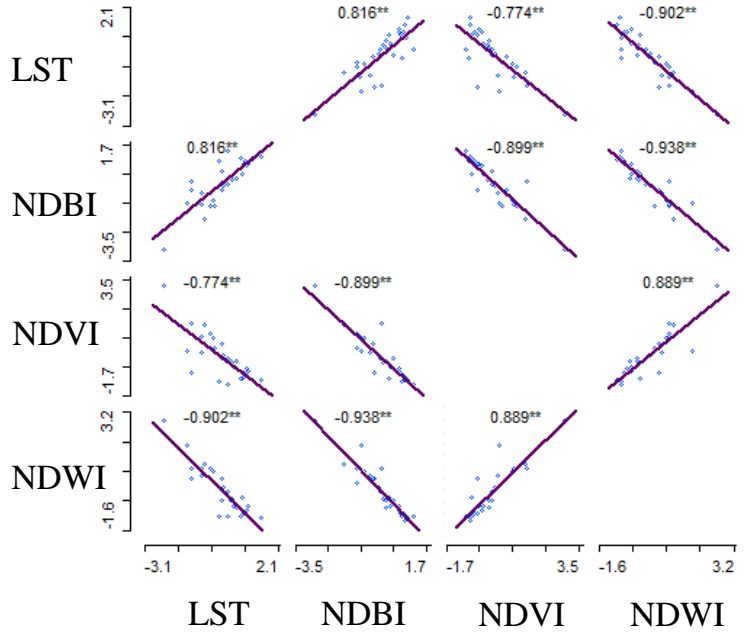

Figure 8. Relationship between LST and other indices with its corresponding slope of linear fit

\subsection{GRID-LEVEL HOTSPOT ANALYSIS}

A barangay-level map was overlaid on the Univariate Local Moran's I clustermap to easily associate the pixels to the corresponding barangay as displayed in Figure 9. Based on the analysis results displayed in Table 3 , highly built-up barangays have higher number of pixels that are considered as hotspots like barangays Tipolo, Bakilid, Ibabao-Estancia, Alang-Alang, Guizo, Subangdaku, and Centro. On the other hand, vegetated barangays have higher number of pixels that are considered as coldspots like barangays Casili and Tawason. There are also areas with mixed pixels of hotspots and coldspots like PUD I, Banilad, Paknaan, Looc, Labogon, Umapad, and Cabancalan.

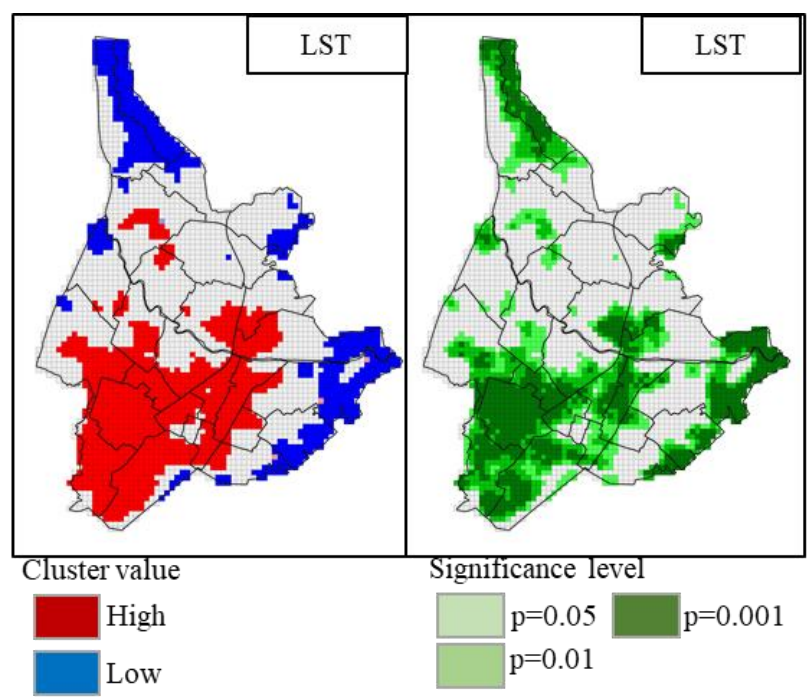

Figure 9. Univariate Local Moran's I cluster and significance maps of Mandaue City

\begin{tabular}{clll}
\hline & Barangay & $\%$ Hotspot & $\%$ Coldspot \\
\hline Hotspots & Tipolo & 100 & 0 \\
& Bakilid & 100 & 0 \\
& Ibabao- & & \\
& Estancia & 93.5 & 0 \\
& Alang-Alang & 87.2 & 0 \\
& Guizo & 84.4 & 0 \\
& Subangdaku & 84.1 & 0 \\
& Centro & 79.4 & 0 \\
\hline Coldspots & Casili & 0 & 100 \\
& Tawason & 0 & 52 \\
\hline Mixed & PUD I & 75.6 & 4.8 \\
and & Banilad & 33.1 & 2.8 \\
coldspots & Paknaan & 26.3 & 26.8 \\
& Looc & 14.3 & 17.6 \\
& Labogon & 22.2 & 4.6 \\
& Umapad & 7.4 & 44.5 \\
& Cabancalan & 6.6 & 17.8 \\
\hline
\end{tabular}

Table 2. Percentage of hotspot and coldspot pixels

All of the pixels in Barangay Tipolo are considered hotspots due to the abundance of urban structures composed of concrete and asphalt that have higher thermal conductivity and heat capacity (Gartland, 2012). In comparison, Barangay Casili is a highly vegetated area with grass, shrubs and trees. Vegetation has lower heat storage and exhibits evapotranspiration reducing surface temperatures that is why all of its pixels are considered coldspots as shown in Figure 10.

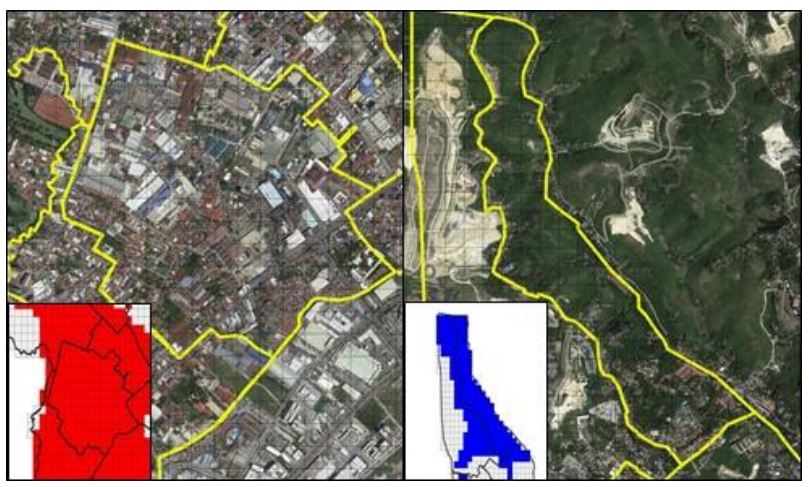

Figure 10. Grid analysis on barangay Tipolo (left) with $100 \%$ hotspot pixel count and barangay Casili (right) with $100 \%$ coldspot pixel count

There are pixels within barangays that have different cluster values and deviate from their neighboring pixels. These areas are composed of different materials. Barangay Ibabao-Estancia (Figure 11) is characterized by abundant urban structures though there is an area filled with trees which is not considered as a hotspot because it has lower surface temperature compared to the neighboring areas. Trees provide shade and exhibit evapotranspiration that reduce surface temperatures (Gartland, 2012). On the other hand, the northeast part of Barangay Umapad (Figure 11) is considered a coldspot because it is highly vegetated mostly composed of mangroves. However, there are certain pixels within the area that are not considered as coldspots. These 
pixels are situated at the dumpsite area. The dumpsite area has a different material composition of concrete, plastics, metals and wastes. These materials have higher thermal conductivity and heat capacity that increase surface temperatures (Gartland, 2012).

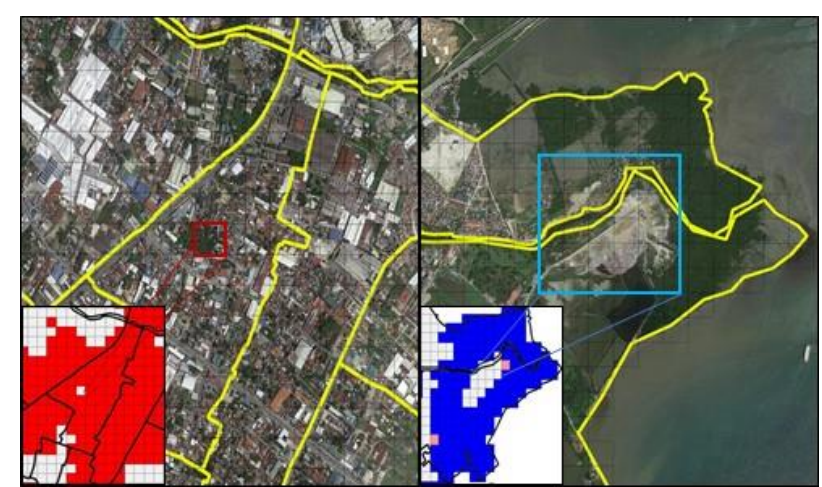

Figure 11. Grid analysis on barangay Ibabao-Estancia (left) with $93.5 \%$ hotspot pixel count and barangay Umapad (right) with $7.4 \%$ hotspot, $44.5 \%$ coldspot pixel count

\section{CONCLUSION}

Using spatial and temporal analysis of LST, it was found out that urban heat island phenomenon occurs in Mandaue City. Highly dense built-up barangays located at the southwest and center part of Mandaue City have high average LSTs compared to the vegetated barangays located at the northeast and southeast part of Mandaue City with low average LSTs. Comparative analysis of the relationships between LST and the other indices indicated that there is a linear relationship between LST and NDBI while inverse relationships between LST with NDVI and NDWI. Gridlevel analysis results indicated that pixels with surface material composition of asphalt, concrete and metals are considered as hotspots. Built-up barangays like barangays Tipolo, Bakilid, Ibabao-Estancia, Alang-Alang, Guizo, Subangdaku, and Centro have higher number of hotspot pixels. On another hand, pixels with vegetation are considered as coldspots. Vegetated barangays like Casili and Tawason have higher number of coldspot pixels. There are also barangays that have mixed pixels of hotspots and coldspots due to varied surface material composition in different areas. The results of this study can provide reliable information for urban planning. Future studies should include other urban parameters in analysing LST.

\section{ACKNOWLEDGEMENTS}

This work is primarily funded by the PCIEERD-DOST with Project No. 4028, 2019. The field validation was conducted with the support of Mandaue City Planning and Development Office, and City Environment and Natural Resources Office.

\section{REFERENCES}

Castillo, A. Del. (2018). CITY's ECONOMIC PROFILE. Retrieved from: https://www.mandauecity.gov.ph/about/cityseconomic-profile

Deilami, K., Kamruzzaman, M., \& Liu, Y. (2018). Urban heat island effect: A systematic review of spatio-temporal factors, data, methods, and mitigation measures. International Journal of Applied Earth Observation and Geoinformation, 67(November

\section{7), 30-42. https://doi.org/10.1016/j.jag.2017.12.009}

Fathizad, H., Tazeh, M., Kalantari, S., \& Shojaei, S. (2017). The investigation of spatiotemporal variations of land surface temperature based on land use changes using NDVI in southwest of Iran. Journal of African Earth Sciences, 134, 249-256. https://doi.org/10.1016/j.jafrearsci.2017.06.007

Gao, B. C. (1996). NDWI - A normalized difference water index for remote sensing of vegetation liquid water from space. Remote Sensing of Environment, 58(3), 257-266. https://doi.org/10.1016/S0034-4257(96)00067-3

Gartland, L. (2012). Heat Islands: Understanding and mitigating heat in urban areas. In Heat Islands: Understanding and Mitigating Heat in Urban Areas (Vol. 9781849771). https://doi.org/10.4324/9781849771559

Hasanlou, M., \& Mostofi, N. (2015). Investigating Urban Heat Island Effects and Relation Between Various Land Cover Indices in Tehran City Using Landsat 8 Imagery. $\mathrm{f004.}$ https://doi.org/10.3390/ecrs-1-f004

Huntington, J. L., Hegewisch, K. C., Daudert, B., Morton, C. G., Abatzoglou, J. T., McEvoy, D. J., \& Erickson, T. (2017). Climate engine: Cloud computing and visualization of climate and remote sensing data for advanced natural resource monitoring and process understanding. Bulletin of the American Meteorological Society, 98(11), 2397-2409. https://doi.org/10.1175/BAMS-D$15-00324.1$

Isa, N. A., Wan Mohd, W. M. N., \& Salleh, S. A. (2013). The effects of built-up and green areas on the land surface temperature of the Kuala Lumpur City. International Archives of the Photogrammetry, Remote Sensing and Spatial Information Sciences - ISPRS Archives, 42(4W5), 107-112. https://doi.org/10.5194/isprs-archives-XLII-4-W5-107-2017

Jamei, Y., Rajagopalan, P., \& Sun, Q. (Chayn). (2019). Spatial structure of surface urban heat island and its relationship with vegetation and built-up areas in Melbourne, Australia. Science of the Total Environment, 659, 1335-1351. https://doi.org/10.1016/j.scitotenv.2018.12.308

Kaplan, G., Avdan, U., \& Yigit Avdan, Z. (2018). Urban Heat Island Analysis Using the Landsat 8 Satellite Data: A Case Study in Skopje, Macedonia. 5171. https://doi.org/10.3390/ecrs-205171

Kikon, N., Singh, P., Singh, S. K., \& Vyas, A. (2016). Assessment of urban heat islands (UHI) of Noida City, India using multi-temporal satellite data. Sustainable Cities and Society, 22, 19-28. https://doi.org/10.1016/j.scs.2016.01.005

Levermore, G., Parkinson, J., Lee, K., Laycock, P., \& Lindley, S. (2018). The increasing trend of the urban heat island intensity. Urban Climate, $24, \quad 360-368$. https://doi.org/10.1016/j.uclim.2017.02.004

Liu, L., \& Zhang, Y. (2011). Urban heat island analysis using the landsat TM data and ASTER Data: A case study in Hong Kong. Remote Sensing, 3(7), 1535-1552. https://doi.org/10.3390/rs3071535

Macarof, P., \& Statescu, F. (2017). Comparasion of NDBI and NDVI as Indicators of Surface Urban Heat Island Effect in Landsat 8 Imagery: A Case Study of Iasi. Present Environment 
and Sustainable Development, Vol. 11, pp. 141-150. https://doi.org/10.1515/pesd-2017-0032

Mihalakakou, G., Flocas, H. A., Santamouris, M., \& Helmis, C. G. (2002). Application of Neural Networks to the Simulation of the Heat Island over Athens, Greece, Using Synoptic Types as a Predictor. Journal of Applied Meteorology, 41(5), 519-527. https://doi.org/10.1175/1520-

0450(2002)041<0519:AONNTT>2.0.CO;2

Oke, T. R. (1982). The energetic basis of the urban heat island. Quarterly Journal of the Royal Meteorological Society. https://doi.org/10.1002/qj.49710845502

Oke, T. R. (1988). Street design and urban canopy layer climate. Energy and Buildings, 11(1-3), 103-113. https://doi.org/10.1093/nar/21.18.4159

Orhan, O., Ekercin, S., \& Dadaser-Celik, F. (2014). Use of Landsat Land Surface Temperature and Vegetation Indices for Monitoring Drought in the Salt Lake Basin Area, Turkey. The Scientific World Journal, 2014(Vci), 1-11. https://doi.org/10.1155/2014/142939

PAGASA. (2019). Annual Tropical Cyclone Track. Retrieved from:http://bagong.pagasa.dost.gov.ph/information/annualcyclone-track

Santamouris, M. (2013). Using cool pavements as a mitigation strategy to fight urban heat island - A review of the actual developments. Renewable and Sustainable Energy Reviews, 26 , 224-240. https://doi.org/10.1016/j.rser.2013.05.047

Voogt, J. A., \& Oke, T. R. (2003). Thermal remote sensing of urban climates. Remote Sensing of Environment, 86(3), 370-384. https://doi.org/10.1016/S0034-4257(03)00079-8

Yang, L., Qian, F., Song, D. X., \& Zheng, K. J. (2016). Research on Urban Heat-Island Effect. Procedia Engineering, 169, 11-18. https://doi.org/10.1016/j.proeng.2016.10.002

Zha, Y., Gao, J., \& Ni, S. (2003). Use of normalized difference built-up index in automatically mapping urban areas from TM imagery. International Journal of Remote Sensing, 24(3), 583594. https://doi.org/10.1080/01431160304987

Zhou, X., \& Chen, H. (2018). Impact of urbanization-related land use land cover changes and urban morphology changes on the urban heat island phenomenon. Science of the Total Environment, 635, 1467-1476. https://doi.org/10.1016/j.scitotenv.2018.04.091 